\title{
LAPURDUTH
}

Euskal ikerketen aldizkaria | Revue d'études basques |

Revista de estudios vascos | Basque studies review

$9 \mid 2004$

Numéro IX

\section{Astarloaren Discursos filosóficos : iturriak eta axiomak}

\section{Ricardo Gómez}

\section{(2) OpenEdition \\ Journals}

Édition électronique

URL : http://journals.openedition.org/lapurdum/822

DOI : 10.4000/lapurdum.822

ISSN : 1965-0655

\section{Éditeur}

IKER

\section{Édition imprimée}

Date de publication : 1 novembre 2004

Pagination : 117-133

ISBN : 2-68781-376-X

ISSN : $1273-3830$

Référence électronique

Ricardo Gómez, «Astarloaren Discursos filosóficos : iturriak eta axiomak », Lapurdum [Linean], 9| 2004, Sarean emana----an 01 mars 2009, kontsultatu 04 mai 2019. URL : http://journals.openedition.org/ lapurdum/822 ; DOI : 10.4000/lapurdum.822 


\title{
Astarloaren Discursos filosóficos: iturriak eta axiomak
}

\author{
Ricardo Gómez \\ (UPV/EHU eta "Julio Urkixo" Euskal Filologi Mintegia)
}

\section{Sarrera*}

Berriki arte Astarloari buruz izan den iritzia ez da gehienetan oso baikorra izan. Euskararen apologia egin nahian, burugabekeria asko idatzi zituela leporatu zaio maiz apaiz durangarrari. Bereziki kritikatu izan dira bere bi teoria ezagunenak, alegia, euskara gizakion lehenengo hizkuntza izan zela eta lehen hizkuntza hartan - hots, euskaran — letra bakoitzak esanahi bat zuela.

Nolanahi ere, azken urteotan Astarloari buruzko ikuspegia aski aldatu da. Itziar Laka (1989), Xabier Alberdi (1989), Xabier Altzibar (1997) eta beste zenbaiten lanei esker, Astarloaren obraren alderdi onak azaleratzen hasi dira euskalaritzan. Eta lan honetan nik ere Astarloaren merezimenduez jardun nahi nuke, teoria horiek ez zirela hutsetik sortu erakusteko asmoz. Arreta berezia ipiniko dut Astarloak hizkuntzaren jatorriari buruz zituen iritzietan. Izan ere, Astarloaren teoria XVIII. mendean, Frantzian batik bat, arrakasta izan zuen gramatika orokor eta filosofikoaren korrontean koka daiteke, zehazkiago Frantziako gramatikari-filosofo sentsualisten ildoan.

Horretarako, Astarloak bere lanetan aitortzen dituen iturri batzuk aurkezten hasiko naiz (§2). Jarraian, Diskurtso filosofikoen (Astarloa 1883) garrantzia nabarmendu nahi nuke (§3), durangarraren lan azken eta osoena delako. Ondoren, Europan XVIII. mendeko hizkuntz hausnarketetan erabili ziren gai nagusi batzuk azaltzen jarraituko dut (§4). Eta, azkenik, Astarloak hizkuntzaren jatorriaz zituen iritzi eta teoriak burutzeko

\footnotetext{
* Artikulu honen oinarrian aurreko zenbait lan daude: batetik, I Congreso Internacional de la Sociedad Española de Historiografía Lingüística (Coruña, 1997ko otsailaren 18-21) biltzarrean aurkezturiko komunikazioa, geroago Gómez (1999) lanean argitaratu zena; bigarrenik, Hurch, Gómez eta Kerejeta (2002) lanerako prestatu nuen testua; eta, hirugarrenik, Durangon emandako hitzaldi bana jasotzen duten Gómez (2002) eta (2004) artikuluak. Halaber, artikulua burutzeko BFF2002-03132 ikerketa proiektuaren babesa izan dut.
} 
erabili zituen abiapuntuak aurkezten eta euren testuingurua zehazten ahaleginduko naiz $(\S 5)$.

\section{Aitortutako zenbait iturri}

Astarloak ${ }^{1}$ Apologiaren hitzaurrean (Astarloa 1803: v-xxiv) dioskunez, euskarari buruzko interesa 1783 urte inguruan piztu zitzaion; orduz geroztik bere burua euskara aztertzeari eta goraipatzeari eskaini zion. Horretarako hizkuntza askoren hainbat gramatika bildu zituen; honen isla dira bere lanetan aipatzen dituen Europa, Amerika eta Asiako hizkuntzen datu ugariak, inoiz edo behin euskararekin konparatzeko ere erabili zituenak. Euskara aztertzeko erabili zituen iturri idatziak Apologiaren lehenengo orrialdean bertan jakinarazten dizkigu (1803: v). Hauexek dira: Oihenart, Harriet (“Arriet" deitzen badio ere), Moret, Etxabe eta Larramendi. Jakina, Astarloak ez zituen ezagutu Mikoleta eta Urteren eskuizkribuak, Ingalaterran baitzeuden —eta daude-, ezta Larramendik hiztegiaren hitzaurrean (1745: xxxiv-xxxviii) edo Humboldtek (Humboldt 1933 [1810-1815]) aipaturiko beste zenbait lan ere —edo ezagutu bazituen, ez zituen aintzat hartu bederen-. Voltoire-ren irakas-liburua ere (ca. 1620) ez du aipatzen.

Ondoren, Astarloak euskararen perfekzioa frogatzeko hizkuntzaz hizkuntza egindako bidea zehazten digu: latina, hizkuntza erromantzeak, grekoa, hebreera eta beste hizkuntza semitiko batzuk, txinera, ${ }^{2}$ hizkuntza germaniarrak, zeltak, ${ }^{3}$ eslaviarrak eta

\footnotetext{
${ }^{1}$ Astarloaren bizitzari buruzko azterketarik osoena Uriarteren (2002) lan mardul eta bikain dokumentatua dugu. Garaterenak (1936) oraingoz balio du, bere barnean desordena eta nahasmendu handia izanik ere. Lan biografiko aipagarriak dira, orobat, Manterolarena (1921) eta Villabasoren (1887) ia hagiografiko hura.

2 Hizkuntza honetaz Duhalde eta Kircher-en lanak baliatu bide zituen (Astarloa 1803: xiv). Garatek (1936: 110) lehenaren berri eman zigun: Jean Baptiste Dualde edo Du Halde (1674-1743) frantses jesuita izan zen; Astarloak ezagutu zuen lana Description géographique, historique, chronologique, politique et physique de l'Empire de la Chine et de la Tartarie chinoise (Du Halde 1735) izan zitekeen. Bestalde, Du Halde Hizkuntzalaritzaren Historian ezaguna da Lettres édifiantes et curieuses (Du Halde 1702-1776) argitaratu zituelako; izan ere, lan honetako XXVI. liburukian Jean François Pons-ek idatzitako gutun eraginkorra dago, Europako Mendebaldean literatura sanskritoa ezagutzera eman zuena (cf. Rocher 1995). Halaber, Du Halde euskal hiztegi eskuizkribatu baten egile izan zitekeen, egun galdua dena, baina bai Humboldtek ("El famoso Jesuita Du Halde... † en 1743... dejó, pero en un manuscrito casi ilegible, un Diccionario Vasco en 3 volúmenes en folio..."; Humboldt 1817: 111), bai Delattre-k (1949: 1.478)
} 
amerindiarrak. ${ }^{4}$ Halaber, asko baliatu zen Lorenzo Hervásek emandako datuez; izan ere, Idea dell'Universo-ren hogeita bat liburukietatik bost igorri zizkion espainiar jesuitak Erromatik (ziur asko XVIItik XXIera bitartekoak; hau da, Hervás 1784, 1785, 1786, $1787 a, 1787 b) .5$

\section{Diskurtso filosofikoak Astarloaren lanen artean}

Astarloaren lan guztiak (euskarazko bertsoren batzuk izan ezik) euskararen perfekzioei buruzkoak dira eta, beste alde batetik, gaztelaniaz idatziak, apologia lan batean espero denez, bidenabar. Hurrengo lerroetan lan bakar bati buruz jardungo dut, nire ustez

aipatu zutena; azken honek, aldiz, adierazten du Du Halde gaixorik zegoela Bordelen 1762an. Bidenabar, behin baino gehiagotan nahastu da jesuita hau Martin Duhalde euskal idazlearekin (1733-1804); Martin Duhalde apaiza izan zen, baina ez jesuita (cf. Urgell 1997: 646).

Garatek ez digu gauza handirik esaten Kircher-i buruz (Astarloak "Kirker" deitzen dio), beharbada ezagunegitzat jo zuelako. Jakina, Aita Athanasius Kircher (1602-1680) da, China illustrata izeneko lanaren egilea (Kircher 1667); eta hauxe izan zen, ziur asko, Astarloak kontsultatu zuen liburua, agian lehenbizikoz 1670. urtean argitaratu zen haren frantses bertsioa, txinera-frantsesa hiztegi bat gehitzen ziona (cf. Harbsmeier 1992: 298). Kircher, orobat, txineran oinarritutako hizkuntza artifizial baten egitasmoa burutu zuen (Polygraphia nova, 1663), baita egiptoerari buruzko zenbait lan ere (David 1992: 522).

${ }^{3}$ Hizkuntza hauetaz den bezainbatean, Astarloak "los esfuerzos de Valencey" aipatzen ditu (1803: xix). Ezbairik gabe, Charles Vallancey jeneral ingelesaz ari da (1721-1812). Irlandara bidalita, 1772an bertako hizkuntza zeltari buruzko saiakera bat argitaratu zuen eta hurrengo urtean irlanderaren gramatika bat, non defendatzen baitu hizkuntza hau, punikoa, kalmouck eta hizkuntza amerindiar batzuk ahaideak direla (Tourneur 1905: 74). Halaber, historia-lanen Collectanea bat idatzi zuen (Dublin 1770-1804).

4 Astarloaren kritiko garaikideek aipatzen zituen hizkuntzak aski ez ezagutzea leporatu zioten, besteak beste (cf., esaterako, Conde 1803). Astarloak sutsuki defendatu zuen bere burua halako kritiken kontra (Astarloa 1804). Egun, hala ere, aipatu hizkuntzak noraino ezagutu zituen ez da xeheki aztertu.

5 Cf. orobat Astarloa (1803: xxi): "No pude adquirir mas gramáticas por entónces, y procuré suplir esta falta con la lectura de los otros quatro tomos del erudito Hervás. Su orígen de las lenguas me sirvió muchísimo en mis tareas. El diccionario poligloto, la aritmética de las naciones, y sobre todo la excelente recoleccion de la oracion dominical, traducida literalmente al Italiano de un sin número de idiomas, me hicieron ver el mecanismo de ellos". 
Astarloaren obrarik garrantzitsuena eta oparoena den Discursos filosóficos liburuari buruz, alegia. ${ }^{6}$

Diskurtso filosofikoek Astarloaren ideia guztiak aurkezten ditu sistematikoki zortziehun bat orrialdetan zehar. Ez zen 1883 arte argitaratu, baina badakigu euskalari batzuek —Humboldtek, esaterako— eskuizkribua irakurri zutela. Dena den, Justo Garatek (1936) zioenez, oso jende gutxik irakurri bide ditu Diskurtso filosofikoak osorik; eta "gutxi" esateari gehiegitxo esatea dela deritzot.

Lanaren izenburu osoari begiratzen badiogu, diskurtsoen egituraren eta helburuen berri izan dezakegu. Hauxe da: Discursos filosóficos sobre la lengua primitiva ó Gramática y análisis razonada de la euskara ó bascuence. Astarloak berak dioskunez, bere lana bi zatitan banatu du. Lehenengoan ("Sobre si hubo ó no lengua primitiva" izenekoa, 5-112. or.) gizakien jatorrizko hizkuntza bakarra izan zela aldezten du eta hizkuntza haren ezaugarriak finkatzen saiatzen da: lehen hizkuntza bakarra, perfektua, artikulatua eta naturala izan zela dio. Aldiz, bigarren zatian ("Gramática de la lengua primitiva" izenekoa, 113-773. or.), lehen hizkuntza hura oraindik existitzen dela aditzera eman nahi du; hain zuzen, lehen hizkuntzaren ezaugarri guztiak zehaztu ondoren, eurak betetzen dituen hizkuntza bakarra euskara dela erakusten saiatzen da.

Beste autore batzuek —Garate (1936: 143), Castaños (1978: 31) edo Altzibarrek (1992), adibidez - egitura desberdina ikusi dute, bi zatien arteko banaketa beste era batez eginez edota hiru zati proposatuz; baina diskurtsoen testua oso garbia da gai honi dagokionez. Aski luzea bada ere, uste dut Astarloaren pasarte hau oso interesgarria dela bere metodoaren zehaztasunaz ere ohartzeko:

He determinado por lo mismo dividir mis tareas en dos partes y varios discursos en los cuales procuraremos averiguar con el mayor empeño: En el primero, si hubo ó nó un idioma primitivo, quiero decir, si los primeros hombres hablaron ó nó el lenguaje perfecto, desde el mismo instante en que fueron criados. Discurriremos tambien sobre si este idioma fue de accion ó de voces articuladas. Si fue natural al hombre. Si éste lo

\footnotetext{
${ }^{6}$ Uriartek (2002: 526-530) Astarloaren lan guztien — hala inprimatuen nola eskuizkribatuen- zerrenda dakar, iruzkinez horniturik; ik., halaber, Garate (1936) eta Altzibar (1992: 219-226). Astarloaren euskarazko lanari buruz, ik. Uriarte (2002: 458 eta hh.).
} 
adquirió á costa de tiempo y trabajo. Si el Sér Supremo quiso infundirle á nuestros primeros padres. Ultimamente investigaremos si fue uno ó fueron muchos.

En la segunda parte nos esforzaremos en averiguar, si existe ó nó en alguna de las naciones este deseado idioma. Filosofaremos para este efecto con la mayor atencion y escrupulosidad, sobre el mecanismo que hubo de haber tenido un lenguaje de que hicieron uso los primeros hombres. Empezando desde su alfabeto, recorreremos hasta la Sintaxis. No dejaremos, por mínima que sea, cosa alguna sin escudriñarla con el mayor cuidado. Estableceremos cuantas reglas y preceptos sean necesarios, para levantar el gran edificio de un perfecto lenguaje (Astarloa 1883: 1-2)

Laburbilduz, Diskurtso filosofikoen helburua lehen hizkuntza bakarra izan zela eta hizkuntza hura euskara dela frogatzea da.

Aurrera baino lehen, arazo bat azaldu nahi nuke orain, laburki bada ere: Diskurtso filosofikoen datazioari dagokiona, alegia. Astarloaz jandun duten autore gehienek (Gárate 1936: 139, Tovar 1980: 111, eta azken honi jarraiki Laka 1989, Alberdi 1989 eta Altzibar 1992) uste izan dute Diskurtso filosofikoak Apologiaren aurretik idatzi zituela Astarloak; hau da, 1803 baino lehen. Arrazoia da, Garaterentzat, Apologiaren hitzaurrean Astarloak esaten duela Diskurtso filosofikoen zirriborroa bukatua zuela, Hervásek Erromatik bere katalogoaren liburukiak bidali zizkionerako, hamar-hamabost bat urte lehenago ziurrenik (Astarloa 1803: xix). Gainera, Apologiaren orrialdeetan Astarloak sarri aipatzen ditu Diskurtso filosofikoak.

Hala eta guztiz ere, Diskurtso filosofikoak arretaz irakurriz gero, berehala kontura gaitezke euren azken idatzaldia Apologiaren ondoren burutu zuela. Alde batetik, esan berri dudanez, Apologiaren hitzaurrean Diskurtso filosofikoen "zirriborroa" aipatzen da. Bestetik, Diskurtso filosofikoetan Apologia aipatzen da, eta ez gutxitan. Areago dena, Apologian Diskurtso filosofikoen aipamen guztiak geroaldian egiten ditu Astarloak eta Diskurtso filosofikoetan, berriz, Apologia lehenaldian aipatzen du (ik., adibidez, Astarloa 1883: 44, 78, 160, 185, etab.). Baina, nire iritziz, guztiz erabakigarria gertatzen dena hauxe da: Diskurtso filosofikoetan, noiz edo behin, Astarloak Apologiaren orrialdea ere zehazten du (ik., adibidez, Astarloa 1883: 187); edo Apologian erabilitako terminologia beste era batera ematea proposatzen $\mathrm{du}$ :

En nuestra Apología en lugar de impulsiva llamamos causal á la última posposicion [-gatti]; pero habiéndonos hecho ver varios literatos que esta voz causal era confusa 
para indicar la idea que con ella se queria dar á entender, no hemos tenido embarazo en sustituirla por la voz impulsiva... (Astarloa 1883: 348)

Halaber, Apologiari erantzunez Montuengako Apaizak — hots, Juan Antonio Condek1804an idatzitako Censura crítica eta urte berean Astarloak ateratako Reflexiones filosóficas erantzun anonimoa ere aipatzen ditu (Astarloa 1883: 322).

Beraz, esan genezake Humboldtek 1801ean egindako bidaian Diskurtso filosofikoen zirriborro bat ikusi ahal izan zuela, bai. Baina Astarloak obra honen azken idatzaldia 1804tik —Reflexiones filosóficas argitaratu ondotik- 1806an hil bitartean bukatuko zuen edo, beharbada, hil zenean Diskurtso filosofikoak guztiz bukatu gabe utzi zituen. Halako zerbait ematen digute aditzera Juan Bautista Errok Humboldti bidalitako eskutitz batean agertzen diren hurrengo hitzek:

En efecto, tengo en mi poder el Plan de lenguas de nuestro Astarloa, que me lo legó a su muerte con la obra de los 'Discursos filosóficos sobre la primitiva lengua' para que los concluyera y publicara. (apud Gárate 1934: 637)

Alabaina Uriartek Astarloaren artikulu bat azaleratu du berriki, 1805eko martxoaren 15ean Mercurio de España aldizkarian agertu zena; bertan Astarloak hauxe adierazten du: "me hallo preparando para la prensa mis discursos filosóficos, que ya están concluidos". Era berean, Uriartek Diskurtso filosofikoak Astarloaren bizialdian ez argitaratzeko arrazoi posibleak ematen eta lekukotzen ditu (Uriarte 2002: 280-284).

\section{XVIII. mendeko hizkuntz ideiak Europan}

Astarloaren proposamenak behar bezala ulertuko badira, guztiz komeni da bere garaiko hizkuntz ideien azalpenean apur bat luzatzea. Astarloak garaiko iturrietan edan zuen eta euren aztarnak erraz antzeman daitezke bere lanetan. Europako XVIII. mendeko hizkuntzalaritzaren ardatzak hiru gai nagusitan bildu ditut: gramatika orokorraren zabalkundea (§4.1.), hizkuntzaren jatorriari buruzko eztabaidak (§4.2.) eta munduko hizkuntzen datu-bildumak (§4.3.).

\subsection{Gramatika orokorraren zabalkundea}

Oro har, gramatika orokorrari hizkuntzaren arazo orokorren gaineko hausnarketak dagozkio. Hizkuntzalaritzaren joera honek oso tradizio luzea du Europako 
Mendebaldean: Erdi Aroaren amaieran, latinean oinarrituz, modistae izeneko filosofo eskolastikoek hizkuntza guztiek funtsean gramatika berdina zutela baieztatu zuten. Orobatsu Humanismoaren garaiko zenbait gramatikari filosofok, hala nola Scaligero, Sanctius, Vossius, Campanella, etab. Baina gramatika orokorrari erabateko ospe eta arrakasta eman zizkionak Paris ondoko Port-Royal komentu-eskolan egindako lanak izan ziren: Grammaire générale et raisonnée (Arnauld \& Lancelot 1660) eta La logique (Arnauld \& Nicole 1662), hain zuzen.

Port-Royaleko lanek helburu bikoitza bete nahi zuten. Alde batetik, hizkuntzaren arau orokorrak aurkeztea eta, bestetik baina loturik, edozein hizkuntza ikasteko gida erraz bat lortzea. Neurri handi batean Descartesen arrazionalismoan oinarritu zirelarik, lan hauen ideia nagusiak hauexek dira: hizkuntza giza gogoaren eragiketen isla da eta, hortaz, gramatika ere bai; gizaki guztiongan gogoa bat bera denez gero, gramatika ere bat bakarra da.

Port-Royaleko autoreek Gramatikan eta Logikan garatu zituzten analisietan xeheki jarduteko tokia ez delarik, ${ }^{7}$ aipa dezadan lan hauek arrakasta handia lortu zutela eta euren eragina XVIII. eta XIX. mendeetan luzatu zela. Baina, hizkuntzalaritza historikokonparatzaile berria Alemaniatik gainerako herrietara zabaltzen zen heinean, gramatika orokorraren pisua eta omena apalduz joan ziren.

Nolanahi ere, gramatika orokorraren helburuak eta formulazioak nahiko aldatu ziren XVIII. mendean zehar, lehenbizi entziklopedisten eraginez (Beauzée, Du Marsais), geroago filosofo sentsualisten eskutik (Condillac nagusi) eta, Frantziako Iraultzaren ondoren, ideologoen bitartez (Destutt de Tracy, Maine de Biran, Thurot eta Garat euskalduna, besteak beste). Gramatika orokorraren tradizio luzean beste deitura batzuk erabili —eta sarritan nahastu — dira: "gramatika filosofikoa", "gramatika arrazoitua" eta, Ingalaterran batez ere, "gramatika unibertsala". Euren berezitasunak gorabehera, autore guztiok bilduko dituena hauxe da: gramatikaren hatsarreak ideien jatorriari buruzko dotrina batetik eratortzeko ahalegina.

\footnotetext{
7 Port-Royaleko lanez, ik. besteak beste, Harnois (1929), Donzé (1967), Auroux \& Clérico (1992), Dominicy (1992) eta Wheeler (1995).
} 


\subsection{Hizkuntzaren jatorriari buruzko eztabaidak}

XVIII. mendea hizkuntzaren jatorriari buruzko hausnarketen mendea da. ${ }^{8}$ Interes hori giza erakunde eta kulturaren jatorriari buruzko ardura orokorrago baten testuinguruan kokatu behar dugu. Bestalde, hizkuntzaren alderdi teologikoarekin —lingua adamica, lehenengo hizkuntzaren perfekzioa, etab. - hertsiki lotuta dago. Gauzak horrela, hizkuntzaren jatorriaren berreraiketa-saioetan datu enpirikoak eta asmaketa fantastikoak nahasian aurkitzen ditugu maiz. ${ }^{9}$ Aspaldixko Kuehner-ek (1944) hiru teoriatan bildu zituen honelako gogoetak: teoria tradizionala, teoria konbentzionala eta teoria sentsualista izendatu zituenak.

a. Teoria tradizionala Biblian oinarritzen da, nahiz eta Bibliak hizkuntzaren jatorriaz ez duen ezer zehatzegirik esaten. Teologiatik abiatzen den teoria honek, hortaz, hizkuntzak jainkozko etorkia duela baieztatzen du: Jainkoak Adami eman zion hizkuntza (lingua adamica) eta hizkuntza horretatik sortu dira gainerakoak. Eskuarki Adamen hizkuntza hebreera izan zela uste zen, Elizaren iritzi "ofizialari” eta Elizaren barruko tradizio luze bati jarraituz. Nolanahi ere, XVI. mendetik aurrera behinik behin, hebreeraren aldeko aho batezko iritzia ahulduz doa eta beste hautagai batzuk azalduko dira eztabaidagarri. Ordea, hizkuntza guztiak hizkuntza bakar batetik datozelako ideiak —hizkuntzen monogenesiak — sendo jarraituko du.

Hautagai berriok, batzuetan arrazoi nazionalistengatik, eta beste batzuetan europarrek aurkitutako hizkuntza "exotikoekiko" lilura dela-eta proposatuko dira gehienbat. Horrela, Flandesko zenbait autorek -Goropius Becanusek XVI.aren hondarrean edo Myliusek XVII.ean - lehen hizkuntza nederlandera izan zela aldeztu zuten (Droixhe 1978). Edo, 1692an John Webbek bezala, beste autore batzuek txinera nahi izango dute maila horretan ezarri (Simone 1998).

Gaurko ikuspegitik erabat fantasiatsu eta zentzugabekoak iruditu ahal zaizkigu horrelako iritziak. Baina kontuan hartu behar da euren azken helburua ez zela

\footnotetext{
${ }^{8}$ Garai hartako eta lehenagoko teoriez eta eztabaidez, ik., besteak beste, Harnois (1929), Kuehner (1944), Juliard (1970), Aarsleff (1982 [1976]), Droixhe (1978) eta Salmon (1995).

9 Eztabaida hauek une gorena bizi izan zuten XVIII. mende bukaeran, 1770ean Berlingo Zientzia Akademiak hizkuntzaren jatorria erabakitzeko lehiaketa bat deitu zuenean (ik., adibidez, Salmon 1995).
} 
linguistikoa bakarrik; erlijioso eta mistikoa ere bazen: Jainkoaren hizkuntzaren eta hizkuntza historikoen arteko loturak zehaztu eta, honekin batera, hizkuntzaren eta munduaren arteko loturak ere zehaztu nahi zuten (helburu hauei loturik kokatu behar dugu, esaterako, juduen Kabalaren tradizioa).

Jakina, teoria tradizionalari eustea fede kontua zen, ez zegoen frogatzerik. Horregatik, XVIII. mendean — arrazoiaren mendea, ez ahaztu- bestelako azalpenak bilatu ziren, arrazoiaren menpe, ez fedearen menpe izan zitezkeenak. Horretarako abiapuntua gizakien natura bakarra eta aldaezina zela pentsatzea izan zen.

b. Hortaz, XVII. eta XVIII. mendeetako arrazionalismo frantsesaren babespean, lingua adamicaren ideia bera ere gainbehera abiatu zen. Honen kariaz, teoria konbentzionala deiturikoan gizakiek berezko ideiak dituztela (arrazionalismoaren hatsarrea berau) eta hotsak ahoskatzeko ahalmena ere badutela proposatzen da. Ondorioz, teoria honek planteatzen du lehen gizakiek hizkuntza asmatu egin zutela, euren ideiak ahoz islatzeko eta, horrela, komunikatzeko gogoa bete eta berez duten gizartekotzeko izaera adierazteko. Teoria honen aldekoentzat arrazoiaren eta hizkuntzaren arteko lotura logikoa frogatzea aski zen gizakiek hizkuntza asmatu zutela ziurtatzeko eta, beraz, logikaren argudioez baliatu ziren gehienbat.

c. Sentsualistak filosofia enpiristaren jarraitzaileak ziren. Teoria sentsualistaren iritziz, gizakiok ideiak —eta, oro har, ezagutza guztiak— zentzumenen bitartez jasotzen ditugu, pixkanaka jaso ere; hau da, ez dago berezko ideiarik. Hortaz, hasiera batean gizakiek ez zuten ideiarik eta, beraz, ez zuten hizkuntzarik, sentsualista gehienek lehen gizakia basatia zela uste baitzuten. Aurreneko sentsazioekin gizakiak hotsak ahoskatu zituen, edo gorputz-atalen bat mugitu zuen. Pixkanaka hots eta mugimendu horiek analizatu zituen eta horrela ideiak aurkitu. Une horretara iritsita, gizakia gauza zen keinu eta hots horien esanahiak finkatzeko eta, ideia berriak jaso ahala, keinu eta hots berriak sortzeko ere.

Sentsualistek tradizionalisten eta konbentzionalisten ideiak baztertu nahi izan zituzten; alabaina ezin izan zioten euren eraginari erabat ihes egin. Izan ere, Bibliako kronologia onartu ohi zuten, bai eta hebreerari lehentasuna eman ere. Bestalde, arrazoiaren eta hizkuntzaren arteko lotura logikoan sinesten zuten. Haatik, konbentzionalisten arazoa hizkuntzaren jatorria bazen, sentsualisten arazoa bikoitza da: 
hizkuntzaren jatorria eta hizkuntzaren garapena azaldu behar dituzte. Azken gai honetaz bi joera daude sentsualisten artean: ekintza eta keinuen aldekoa (Condillac buru) eta aho-hizkuntzaren aldekoa (De Brosses eta Court de Gébelinek aldeztu zutena).

Étienne Bonnot Condillac (1714-1780) XVIII. mendeko filosofo frantses ezagunenetakoa dugu. Gizakien komunikatzeko lehen bideak instintuak agindutako keinuak izan zirela uste zuen (langage d'action edo ekintza-hizkuntza deitu zion). Hasierako keinu basati haien ondoren, keinu apalagoak eta oihuak etorriko ziren. Pixkanaka, keinu eta oihuen errepikapenari esker, gizakiek elkarren ekintzak eta berauen zergatiak lotuko zituzten, esanahiak ikasiz. Harrezkero, aho-hizkuntzaren erabilgarritasunaz oharturik, ideia edo objektu berriak izendatzeko gero eta hitz gehiago sartzen hasi ziren, eta hitz horien esanahiaz ados jarri ziren. Baina zenbait belaunaldi igaro arte, aho-hizkuntza ez zen ekintza-hizkuntza bezain erabilia izango.

Charles de Brosses (1709-1777) filosofoak, berriz, uste zuen lehen gizakiak hasierahasieratik berezko hizkuntza bat hitz egin zuela. Ondorengo lan bakarra hizkuntza hori garatzea izan zen. De Brossesek ez zuen, beraz, ekintza-hizkuntzaren lehentasunean sinesten. Aitzitik, uste zuen lehen hizkuntzaren itxura hizkuntza ezagunak aztertzetik abiatuz igar zitekeela, baina ez zegoen oso seguru metodoaren fidagarritasunaz. Ondorioz, alderantzizko metodo bat proposatu zuen, alegia aldez aurretik lehen hizkuntzaren hotsak zein ziren finkatzen, euren esanahiak zein ziren aurkitzen eta, ondoren, hizkuntza ezagunekiko loturak bilatzen ahalegintzea. Lehen hotsak aurkitzeko, mintzoaren organoetako atalak hartu zituen kontuan. Horrela, zazpi bokal eta hamazazpi kontsonante proposatu zituen. De Brossesek uste zuen kontsonante bakoitzak bere esanahia zuela; aldiz, bokalek funtsean kontsonanteak lotzeko balio zutela. Hitzak osatzeko, lehen gizakiak hotsak konbinatu behar zituen, halako moduz non gizakiak deskribatu nahi zuen objektua hitzak era egokienean azaltzen zuen. Hortaz, hitzen formaren eta esanahiaren artean lotura naturala dagoela aldezten du. De Brossesek ez du pentsatzen hebreera lehen hizkuntza izan zenik; izan ere, ez du uste lehen hizkuntza hizkuntza ezagunen artean aurki daitekeenik.

Azkenik, Antoine Court de Gébelin (1725-1784) aipatu nahi nuke. Sentsualisten eta tradizionalisten bitartekotza egin nahi izan zuen autore honek, arrazoia eta fedea adiskidetuz. Ildo honetatik, Jainkoak gizakiarengan hizkuntz ahalmena eta jakintza sorrarazi zituela defendatu zuen, baita hizkuntz ahalmenarekin batera mintzoaren 
organoak ere eman zizkiola. Gizakiak, gero, arrazoia eta hizkuntza garatuko zituen, naturaren aginduei jarraituz.

Funtsean, De Brosses eta Court de Gébelin hizkuntzaren jatorriari buruzko teorietan Condillaci jarraitu zioten. Bada, hala ere, diferentziarik: Condillacek hizkuntzaren eraketan gizakiari eman zion indarrik handiena; De Brossesek, aldiz, naturari; Court de Gébelin, azkenik, natura eta gizakia elkartzen saiatu zen, Jainkoaren goiargia ere baztertu gabe.

\subsection{Munduko hizkuntzen datu-bildumak}

XVIII. mendearen azkeneko eta XIX.aren aurreneko laurdenetan hizkuntzen datu-bilduma handiak agertu ziren (ik. Morpurgo Davies 1998, Simone 1998). Hizkuntza askoren testu eta datu bildumak Berpizkundean hasiak ziren, aurkikuntza geografikoekin batera eta berauek sortutako erlijiozko eta merkataritzazko premiek eraginda. Garai hartako bilduma ezagunena, ziurrenik, Konrad Gesner-en Mithridates (1555) dugu, Aita Gurearen hogeita bi bertsio bildu zituena. Berpizkundetik aurrera, datu-bilketan sekulako lana egin zuten misiolariek, bai Ameriketan eta bai Ekialdeko herrietan ere. Orobat, garrantzitsua deritzot nabarmentzeari misiolariek —batik bat, jesuitekmunduko bazter guztietatik bidalitako lanak Europan, eta bereziki Italian, jaso zirela, bilduma orokorragoak burutu ahal izan zirelarik. Inoiz "Vatikanoko hizkuntzalaritza" deitu zaio honi eta hortxe kokatu behar dugu Lorenzo Hervás espainiarraren lan mardula, esaterako.

Izan ere, XVIII. mendeko lan ezagunenak, Hervásen katalogoa (1784an italieraz eta, aski aldaturik, 1800-1804an gaztelaniaz argitaratua) eta Adelung eta Vater-en Mithridates (1806-1817) ditugu. Hervásek Europa, Amerika eta Asiako hirurehun bat hizkuntzaren berri eman zuen. Bestalde, hizkuntza horietako zenbaiten gramatikak ere idatzi zituen, Humboldtek erabiliko zituenak. Adelungek, bere aldetik, bostehun bat hizkuntzaren datuak sartu zituen. Oroit bedi Humboldtek euskarari buruzko datuen iruzkinak egin zizkiola (Humboldt 1817).

Baina, hain ezaguna ez bada ere, garai hartako lan handiena Pallasena izan zen, 1786an argitaratua. Europa eta Asiako berrehun hizkuntza harturik, bakoitzaren 285 
hitzetako zerrenda ematen du. Bigarren argitalpenean (1790-1791koan) Pallas 272 hizkuntzatara iritsi zen, Amerika eta Afrikako zenbait ere sartu baitzituen.

Bilduma hauek guztiak Berpizkundean hasitako munduko hizkuntzak gramatiken bitartez deskribatzeko prozesuari lotuta ulertu behar dira. Izan ere, gramatizazio prozesu honek munduko hizkuntzen arteko ezberdintasunak agerian ipini zituen. Hau da, edozein hizkuntzaren gramatika egiteko ordu arte erabili ohi zen latindar gramatikaren ereduak hizkuntzen nolabaiteko aurkezpen bateratua eskaintzen zuen. Baina, lur berrietan hizkuntza berriak aurkitu eta euren berezitasunak nabaritu zirelarik, ustezko bateratasuna nahikoa ilun eta nahasia agertzen hasi zen. Hortaz, etengabe ugaltzen ari ziren datu bitxi horiek biltzeko eta sailkatzeko beharra sumatu zen.

Halarik ere, lan hauek ez dira bilduma hutsak. Gauza jakina da edozein datu-bilketa aurreiritzi teoriko batzuei lotzen zaiela. Horrela, bilduma hauen egileek hizkuntzen bitartez herrien historia ere ezagutu nahi zuten. Eta, ildo honetatik, hizkuntzen arteko lotura genetikoak proposatu zituzten, batzuetan asmatuz, bestetan ez. Honekin batera, hizkuntzaren jatorriari buruzko teoriak ere azaldu zituzten lan hauetan, egile gehienek hizkuntzen monogenesian eta hebreeraren lehentasunean sinesten zutelarik. ${ }^{10}$ Halaber, hizkuntz bilduma hauek XIX. mendeko gramatika konparatzaileari material baliagarriak eskaini zizkioten, nahiz eta maizegi euren antolamenduak konparaketa-lana oso nekeza bihurtuko zuen.

Aldi berean, eta paradoxikoa badirudi ere, datu-bilduma handi hauek, esan bezala, munduko hizkuntzen arteko desberdintasunez ohartzeko balio izan zuten eta, ondorioz, hizkuntzen monogenesiari buruzko zalantzak sorrarazteko abiapuntu ere suertatu ziren. Hots, munduko hizkuntzak hain desberdinak izanez gero, nekez sor zitezkeen denak aurreneko hizkuntza bakar batetik. Halako gogoetak egin zituzten garai hartako autore batzuek, ez askok baina.

\footnotetext{
10 Honelakoak ditugu, besteak beste, Hieronimus Megiser-en Thesaurus polyglottus (1603), Etienne Guichard-en Harmonie étimologique (1606) eta Ingalaterran 1657-1669 bitartean argitaratu zen Biblia sacra polyglotta (Simone 1998).
} 


\section{Hizkuntzaren jatorriari buruzko teoriak. Astarloaren abiapuntuak}

Aurreko gaiak nabarmendu nahi izan ditut, ahal den neurrian, hain kritika gogorrak jaso dituzten Astarloaren ideiak beren testuinguruan kokatzeko. Izan ere, urte batzuk falta ziren Europan hizkuntzalaritza historiko eta konparatzaileak indarra har zezan, eta askoz urte gehiago joera berriak Frantziako eta Espainiako hizkuntzalaritza tradizioetan sustraitu zitezen.

Astarloaren hizkuntz ideiez hitz egiteko, Koldo Mitxelenak durangarrari buruz azaldu zuen iritziarekin hasiko naiz:

[Astarloa] es además un excelente exponente —más bien tardío— del racionalismo del Siglo de las Luces aplicado a la lingüística [...]. El partir de supuestos falsos, por lo demás no originales, hizo que malograra sus dotes de pensador riguroso y sistemático. (Mitxelena 1988 [1960]: 113)

Mitxelenaren diagnostikoarekin guztiz ados nago. Alabaina puntu bat nabarmendu nahi nuke: Astarloaren ideiak ez daude bere garaikideen ideietatik erabat urrun, ez dago bere sasoitik at. Astarloaren oinarri linguistiko eta filosofiko gehienak, ikusiko dugunez, De Brosses eta Court de Gébelinen ideiekin lotzen dira. ${ }^{11}$

Astarloaren obra guztian zehar hizkuntzaren jatorriari buruzko lau axioma edo oinarrizko sinesmen aurkitzen ditugu: lehen hizkuntza bakarra izan zen (hizkuntzen monogenesia); lehen hizkuntza gizakiengan naturala izan zen, lehen hizkuntza hastapenetik artikulatua izan zen, eta lehen hizkuntza perfektua izan zen. Honela laburtzen ditu Astarloak bere proposamenak:

...estableceremos cuatro proposiciones: $1^{\text {a }}$ Que los primeros hombres hicieron uso de la facultad del habla, desde el primer instante de su creacion. $2^{\text {a }}$ Que el lenguaje que hablaron no fué el de la accion, sino un lenguaje de voces articuladas y significativas. $3^{\mathrm{a}}$ Que este lenguaje no fué infuso por Dios, ni adquirido por el hombre, sino natural. $4^{\mathrm{a}}$ Que el primitivo idioma fué uno y no muchos. (Astarloa 1883: 7)

\footnotetext{
11 Alberdik (1989), ordea, deklinabideari buruzko Astarloaren analisiaz den bezainbatean, Beauzée eta du Marsais entziklopedistei atxiki nahiago du.
} 


\subsection{Lehen hizkuntza bakarra izan zen}

Lehenik, Astarloak, elizgizona zenez gero, hizkuntzen monogenesian sinesten zuen; ezinbestekoa gertatzen zitzaion ia. Ez zuen sinesten, haatik, lehen hizkuntza hebreera izan zela (oroit bedi, garai hartako ideia hedatuena zela kristauen artean) eta euskarari ezarri nahi izan zion ohore hori.

Ordurako — gorago ikusi dugu — hebreeraren lehentasuna kolokan zegoen, aspalditik beste hautagai batzuk proposatu zirelarik. Gogoan izan bedi artean onesten zen munduaren kronologia Biblian oinarritzen zela - Darwinen iraultza arte halaxe izan zen eta-. Denbora bitarte laburra zen, beraz, eta honek gizakien jatorrizko hizkuntza eskurakoia zela pentsarazten zien ikerlariei, baita ezagutzen zituzten hizkuntzetan munduko lehen hizkuntzaren aztarnak erraz antzeman zitezkeela ere.

Bestalde, Frantziako filosofo gehienak, jatorrizko hizkuntzari buruzko ikuspegi desberdinak izan arren, hizkuntzen monogenesiaren aldekoak ziren (salbuespen bakan batzuk baziren; Voltaire, esaterako). Eta Frantziako autore batzuek, jarrera nazionalista batek hartaraturik, frantsesa zuzenean galieratik zetorrela —eta ez latinetik- adierazi zuten eta, aldi berean, galiera lehen gizakien hizkuntza izan zela frogatzen ahalegindu ziren (Juliard 1970). Honelako ideiak aipatu nahi ditut Astarloaren "txorakeriak" beren neurrian eta beren testuinguruan ulertu behar ditugula erakusteko; hein handi batean, garaiko giroaren fruitu direla aditzera emateko, alegia.

\subsection{Lehen hizkuntza naturala izan zen}

Lehenago azaldu ditut XVIII. mendeko hizkuntzaren jatorriari buruzko hausnarketa nagusiak, hiru teoriatan bil daitezkeenak. Astarloak Diskurtso filosofikoetan teoria hauek guztiak birpasatu ondoren, argi eta garbi teoria sentsualistari lotzen zaio; hau da, gizakiengan hizkuntza naturala dela aldezten du, ikustea edo entzutea naturalak diren zentzu berean. Horrela, Court de Gébelinekin guztiz ados agertzen da, esaten duelarik Jaungoikoak gizakiari hizkuntz ahalmena eta mintzoaren organoak eman zizkiola, eta harrezkero gizakia, naturaren asmoei jarraiki, ahalmen hori garatuz joan dela. ${ }^{12}$

\footnotetext{
12 Astarloak jarrera desberdina hartu zuen Apologian, bertan teoria tradizionalaren alde egin baitzuen. Hala ere, Jaungoikoak lehen gizakiari eman zion hizkuntza euskara izan zela zuzenean adierazten ez badu
} 


\subsection{Lehen hizkuntza artikulatua izan zen}

Bestalde, De Brosses eta Court de Gébelinen antzera —eta Condillacek ez bezalaAstarloak adierazten du lehen hizkuntza ez zela ekintza-hizkuntza izan, aho-hizkuntza baizik. Azkenik, Astarloa Rousseaurengandik urruntzen da, durangarrak giza hizkuntza hasieratik artikulatua, eta ez oihuen bidezkoa, izan zela uste baitu.

\subsection{Lehen hizkuntza perfektua izan zen}

Astarloak obra guztian zehar defendatzen duen beste axioma bat lehen hizkuntzaren perfekzioa da. Sinesmen hau beste ideia batekin dago lotuta: alegia lehen gizakia, sortu zenetik, heldua, gizartekoia eta gorputz eta arimaz gaurkoak bezalakoa zela. ${ }^{13}$ Nolanahi ere, De Brosses eta Court de Gébelinek uste zuten bezala, hizkuntzaren perfekzioa betiere muga batzuen barruan egongo litzateke, hizkuntz ahalmenak eta mintzoaren organoek markatutako mugen barruan, hain zuzen ere. ${ }^{14}$

Astarloak hizkuntza perfektu batek hiru hatsarre bete behar dituela proposatzen du: "egokitasuna" (propiedad), "ekonomia" eta "eufonia". Diskurtso filosofikoen hari

ere, zeharka baieztatzen du, euskara Babelgo hizkuntz barreiaketaren aurrekoa dela dioelarik (Astarloa 1803: 276). Diskurtso filosofikoetan jarrera-aldaketaren arrazoiak azalduko ditu: "No habrá quizá en la filosofía un argumento más robusto contra el idioma natural del primer hombre que el que se forma en la armoniosa extructura del mismo idioma. Cuanto más contemplaba esta admirable extructura desde mis primeros ensayos en los idiomas, tanto más me veía persuadido de que el primitivo no podia ménos de ser infuso al hombre por Dios. Confieso con ingenuidad que esta fué mi más querida opinion hasta que ahora, hará como seis meses ciertas reflexiones que me presentó en esta época la contemplacion del mecanismo que hubo de tener el primitivo idioma, y el cotejo que por entónces renové de este mecanismo, y la facultad del habla, con que dotó al hombre el Supremo Hacedor, me hizo variar de dictámen.” (Astarloa 1883: 91).

13 Cf. "El hombre desde el mismo instante en que recibiño su sér, era adulto, era sociable; la organización de su cuerpo era perfectísima; los ojos, el oido, el olfato, el tacto, el gusto, jugaban de sus funciones con el mayor primor, y trasmitian multiplicadas las ideas al alma y esta hacia un uso completo de sus potencias. Él mismo se proporcionaba su comida; él mismo se movia por donde quería, en una palabra, el primer hombre se hallaba inmediatamente despues de su creacion en la disposicion que hoy se hallan los hombres más robustos, más perfectos" (Astarloa 1883: 23). 
nagusietako bat hiru hatsarreok lehen hizkuntzaren atal bakoitzean nola betetzen ziren zehazki erakustea da. Azken finean, Astarloak hauxe frogatu nahi du: euskara dela hiru hatsarreok erabat betetzen dituen hizkuntza bakarra eta, ondorioz, lehen hizkuntzatzat hartzeko egoki den bakarra.

\subsubsection{Egokitasuna}

Hizkuntza baten egokitasuna formaren eta esanahiaren arteko analogian datza; hau da, formaren eta esanahiaren arteko erlazio naturalean (bestela esanda, ez arbitrarioan). Hizkuntzari buruzko ikuspegi kratilozale honen barruan sartzen da, hain zuzen ere, Astarloaren ideia ezagunena: hotsek ere ${ }^{15}$ badute esanahi naturala. Ideia hau Astarloaren argudiaketaren ardatz nagusietariko bat da. Horrelaxe aurkezten du gure autoreak bere egitasmoa:

Si justificamos que no solo las voces, sino tambien las sílabas y aun las letras, tienen una natural significacion, caerá necesariamente este soberbio edificio: se arruinará el sistema del lenguage de acción, y todo filósofo quedará convencido de que el lenguage de la voz fue el primero que usó el hombre. El empeño es árduo; pero no imposible. (Astarloa 1883: 24)

Hots baten esanahi naturala, Astarloaren teoria honetan, mugimendu artikulatorioen eta mugimenduok adierazi nahi duten kontzeptuaren arteko analogiak ematen du:

No podemos dudar, por lo mismo, que estas consonantes, así como todas las vocales en las diferentes acciones orales con que se profieren, han de tener una aptitud de poder analoguizar los signados de la voz y dar á entender por medio de ella en la mútua comunicacion aquello que se quiera indicar; porque siendo destinadas conocidamente para el uso del habla, la diferencia establecida por naturaleza habia de ser con respecto á la locucion, y para mí la principal mira de esta sábia maestra fué el darlas una aptitud competente para que con estas diversidades pudiesen distinguir los objetos comunicados al mismo paso que los analoguizaban por medio de aquellas cualidades

14 Cf., esaterako, "Fuese natural, ó fuese infuso, hubo de ser perfectísimo el lenguaje de los primeros hombres. Sin embargo, su perfeccion no podia exceder los límites que el Sér Supremo prescribió á la facultad del habla" (Astarloa 1883: 116-117).

15 Astarloak letras dio, garaian ohikoa zen bezala. 
representadas en las expresadas musculaciones orales con que se forman todas y cada una de ellas. (Astarloa 1883: 176)

Nabarmentzekoa da Astarloak ez duela arreta ipintzen hotsaren ezaugarri akustikoetan, ezta letren itxura grafikoan ere. Artikulazioari buruzko interes honetan Frantziako entziklopedistekin, bereziki Beauzéerekin, lot genezake Astarloa. ${ }^{16}$ Esan dezadan, bidenabar, horrela jokatzeak euskarazko hotsen deskribapen artikulatorio nahiko zehatza egiteko aukera ematen diola, ordu arte —eta askoz beranduago arte ereeuskalaritzan aurkituko ez duguna. Silaba baten, hizki baten ${ }^{17}$ edo hitz baten esanahia, beraz, osagai konplexu hauetako bakoitzean agertzen diren hots guztien esanahiak elkartzetik aterako litzateke.

Beste alde batetik, hotsen esanahi naturalaren teoria ere ez da berria. Montuengako Apaizari idatzitako erantzunean, Astarloak berak aitortzen du, hirugarren pertsonan bada ere, hautatu duen sistemaren bitartez Court de Gébelinen proposamenak euskarari aplikatzen ahalegindu dela:

...pues si hubiesen visto aun superficialmente lo que sobre esto escribe Court de Gebelin, no se escandalizarian de que Astarloa haya verificado en el bascuence el sistema que aquel sábio quiso establecer en otros idiomas. (Astarloa 1804: 82)

Astarloak hots, silaba, hizki eta hitzen esanahi naturala frogatzeko erabiltzen duen metodo etimologikoaren adibide egokia begitantzen zait hurrengo pasarte hau:

El instinto que mueve el teclado del órgano de la voz, hará que este forme las voces con la debida analogía al signado que se quiere representar. Se presenta á los primeros hombres como primer objeto comunicable la altura de un monte: irá el instinto á formar la voz á lo más alto del órgano de la voz. Hallará en él tres letras O, G, K, y usará ó de la O sola, ó de Go ó de Ko. Se presenta por segundo objeto otra altura: quieren comunicar este objeto los primeros hombres. No pueden ménos de distinguirle de la

\footnotetext{
16 Entziklopedisten teoria fonetikoa giza anatomiaren ezagutza sakon eta sistematiko batean oinarritu zen. Honen kariaz, Beauzéek frantsesaren hotsen sailkapen arrazoitua eskaini ahal izan zuen, kontsonanteak ahoskune eta ahots-modu desberdinen arabera bereiziz (Swiggers 1984).

17 Astarloak característica terminoa erabiltzen du. Bide batez, silabaren eta hitzaren arteko osagai bat bereizteak —nahiz eta ezin dugun erabat gaur "morfema" deitzen dugunaren pare ipinientziklopedistengandik urruntzen bide du Astarloa (Swiggers 1984).
} 
primera altura, y es preciso hallar la diferencia. Esta consiste en que la segunda altura es puntiaguda: pues el instinto añadirá al $\mathrm{O}$, Go, Ko un letra que indique esta circunstancia. Verá que es adecuada la letra I y formará las voces Oi, Goi, ó Koi. Présentase otra tercera altura. Es superior esta altura ó monte á las otros dos [sic]. Formará el instinto la voz para indicarla, doblando los signos análogos O, Go, Ko, y dirá Oo, Gogo, Koko, etc., etc. De estas primitivas voces formarian los primeros hombres un sinnúmero de derivados. Adoptando por terminacion verbal la sílaba tu por ejemplo, resultaria una multitud de verbos. $O$-tu significaria alturarse ó ponerse en alto ó elevar á alguno. Oo-tu doblaria la significacion de $O$-tu. Por este medio tendrían un dilatado campo para enriquecer el idioma. Con Goi-tu podian significar metafóricamente el vencer, este es, ponerse sobre alguno; con Gogo, por la misma metáfora, podian dar á entender todo lo sublime y formar sus derivados; (Astarloa 1883: 67)

Goiko lerroak liburuaren lehenengo zatian daude (oroit bedi, lehen hizkuntzaren ezaugarriei buruzkoan). Hala ere, bertan Astarloak ez du aukerarik galduko irakurlea euskararen datuetarantz gidatzeko, datu horiek adibide argigarri hutsak balira bezala erabiliz. Kontuan izan bedi Astarloaren irakurle gehienek, bere teoriez gogatu nahi dituenek behinik behin, ez zekitela euskaraz. Ostera, aurreko pasartearen azken lerroetara itzuliz gero, irakurle euskalduna laster ohartuko zen bertan agertzen diren adibideak ez direla inondik ere inozenteak, euskal hitzak baitira azaltzen diren goi, otu, goitu eta gogo.

\subsubsection{Ekonomia}

Ekonomia hatsarrearen arabera, naturak eskatzen duen guztia adierazteko ahalik eta baliabide formal gutxien erabili behar ditu hizkuntzak. Honekin lotuta, Astarloak hizkien (características) eta esanahien artean bana-banako egokitasuna dagoela defendatzen du. Ondorioz, hizkuntzaren ekonomia aplikatuz gero, hizkietarik bat hizkirik eza izango da beti; zero morfema $(\phi)$, esan genezake gaur. Ildo honetatik, oso interesgarria deritzot Astarloak zero marka ezartzen dion kategoria, eskuarki, gaur egun semantikoki ere ez-markatutzat hartzen dugun kategoria dela nabarmentzeari: adibidez, 
numeroan singularrari dagokio hizkirik eza, edo kasuen artean absolutibo edo NOR kasuari. ${ }^{18}$

Hizkuntzan ekonomiak parte hartzen duelakoa ez zen, segur aski, ideia berria. Ezin izan dut, alabaina, puntu honetan Astarloaren aitzindaririk aurkitu. Nolanahi ere, Astarloaren merezimendu eta berrikuntza, nik uste, ekonomiaren hatsarrea sistematikoki erabiltzean datza, gramatikaren kategoria eta azpikategoria guztietan aplikatzean, hain zuzen ere (aditzari buruzko adibideetarako, ik. Gómez 1999).

\subsubsection{Eufonia}

Eufonia hizkuntzaren ahoskera zuzena da. Nola ulertzen du hau Astarloak? Haren ustez, ahoa da mintzoaren organo zilegizko bakarra, ez sudurra eta ez eztarria ere. Ondorioz, [v] hotsari "lizuna" (indecente) deritzo, [x] hotsari "animaliena", eta bokal sudurkariak eta hasperena ere arbuiatzen ditu, berauen ahoskatzeko gizakiak sudurra edo eztarria, hurrenez hurren, erabiltzen duelako.

Halaber, silabaren mailako eufonia erregelak ematen ditu. Silaba batean hiru bokal edo bi kontsonante jarraian agertzea debekatzen du. Azkenik, silaben arteko konbinaketei ere zenbait murriztapen fonotaktiko ezartzen dizkie. Adibidez, silaba bat ezin da kontsonante batekin amaitu eta hurrengo silaba kontsonante berberarekin hasi; edo silaba bat ezin da kontsonante herskari batekin amaitu eta hurrengoa edozein kontsonanterekin hasi (hau da, herskari bat ezin da silabaren kodan agertu, egungo terminoetan); edo, azkenik, silaba bat ezin da kontsonante sabaikari batekin amaitu eta hurrengo silaba bokal batekin hasi. ${ }^{19}$

\subsection{Hizkuntz aldaketa eta gramatika unibertsala}

Arazo bat sortzen zaio Astarloari (eta orobat filosofo arrazionalista gehienei): hizkuntz aldaketak eta hizkuntzen arteko desberdintasunek sorrarazten duten arazoa, alegia. Izan ere, gizakien lehen hizkuntza euskara izan bazen, nola jakin dezakegu orduko euskara

\footnotetext{
18 Astarloak artículo deitzen die eskuarki "kasu” izendatzen direnei (ik. Gómez 2001).

19 Silabaren osaketaz arduratu baziren ere, silaba-konbinaketei dagozkien auziak zeharo falta dira entziklopedisten hausnarketetan (Swiggers 1984).
} 
eta oraingoa bat bera dela? Astarloak badaki hizkuntzak denbora joan ahala aldatzen direla baina, beste alde batetik, naturaren asmoak betierekoak direla pentsatzen du.

Egoera horren aurrean honako irtenbide hau ematen du: hizkuntza guztiek gorde dute lehen hizkuntzaren aztarnaren bat; baina, zein gutxiago zein gehiago, naturaren asmoetatik urrunduz joan dira. Eta hizkuntz aldaketaren eragilea gizakia bera izan da. Horrela dio:

No. No fué el instinto; no fué la naturaleza, fué el hombre quién trastornó el arreglado mecanismo del idioma primitivo; quien confundió, oscureció, deshizo aquel admirable órden de la locución que honró las primeras generaciones. [...] No hay lengua, si esceptuamos una, que no haya afeado este mecanismo. Sin embargo, todos los idiomas han conservado rasgos nada equivocos de su belleza. (Astarloa 1883: 77)

Hizkuntza guztiek, beraz, gorde dute lehen hizkuntzatik zerbait. Eta gorde duten ezaugarri bat gramatika egitura da. Astarloaren iritziz, hizkuntzen arteko desberdintasunak ñimiñoak eta azalekoak dira, komunean dutenarekin konparatuz gero. Uste hau aski gertu dagoke gaur egun "Gramatika Unibertsala" deitzen den horretatik:

Corramos paso a paso por todas sus partes constitutivas y hallaremos que esta diversidad de lenguages que tanto se estraña y admira, no es una diversidad intrinseca y esencial, sino muy estrinseca y accidental. [...] Todas [las lenguas] tienen letras, todas tienen silabas: tienen voces, tienen sintaxis. A ninguno de los idiomas faltan palabras primitivas y derivativas, números en los nombres y en los verbos, modos, personas, tiempo. En una palabra, hay tal analogía entre los lenguajes que tan léjos de ser perjudicial su multitud á la unidad del primitivo, la persuade, corrobora y confirma poderosamente. (Astarloa 1883: 101-104)

\section{Hondar oharpenak}

Astarloaren obraren alderdirik ezagunena, ziur asko, letren esanahi naturalari buruzko teoria da; Mitxelenaren (1973: 131) hitzetan, fonema morfemarekin identifikatzea. Hura izan zen, esaterako, Humboldtek Astarloaren ideietatik gehien arbuiatu zuena edo, aitzitik, Arana-Goiriri erakargarri iruditu zitzaiona. Gauza jakina da Arana-Goirik, euskal izendegia berritzean, Astarloak dakarkigun istorio ezagun bat hartu zuela oinarritzat: umeak jaiotzean, arrak badira, ahoskatzen duten lehena $a$ bokala da; emeak badira, aldiz, $e$ bokala. Bistan da bokal bakoitza euskaraz genero bakoitzaren izenarekin 
lotuta dagoela. Baina, era berean, Adam eta Eva lehen gurasoen izenen hasiera letrak ere baditugu.

Hala ere, ahalegindu naiz erakusten Astarloaren lanetan, Diskurtso filosofikoen adibide ezin hobea erabiliz, pasadizo barregarri eta teoria "txoroak" baino askoz gehiago sumatu daitekeela. Nagusiki, hizkuntzaren jatorriari buruzko bere ideia asko Europako gramatika orokor eta filosofikoaren tradizioan erabat txertatzen direla; zuzenzuzenean filosofia sentsualistarekin lot daitezkeela. Orobat, nahiz gaiari leku gutxiago eskaini diodan orrialdeotan, oso nabarmentzekoak dira Astarloaren jokabideak erakusten dituen zehaztasun eta sakontasun ikaragarriak (adibide gehiagotarako, ik. Gómez 2002).

\section{Bibliografia}

Aarsleff, Hans. 1982 [1976]. "An Outline of Language-Origins Theory since the Renaissance”. In From Locke to Saussure, 278-292. Londres: Athlone.

Alberdi, Javier, 1989. "Ohar batzuk euskal deklinabidearen historiografiarako". ASJU 23:2.411-434. Berrargit. in Gómez \& Lakarra, arg. 1992, 67-90.

Altzibar, Xabier, 1992. Bizkaierazko idazle klasikoak. Bilbo: Bizkaiko Foru Aldundia. 1997. Pedro Paulo Astarloa (1752-1806). (Etxezarreta Bilduma, 3). Durango: Arte eta Historia Museoa.

Arnauld, Antoine \& Claude Lancelot, 1660. Grammaire générale et raisonée. Paris. Berrargit. faksim. Stuttgart/Bad Cannstatt: F. Fromman, 1966. \& Pierre Nicole, 1662. L'art de penser: la logique de Port-Royal. Paris. Berrargit. faksim. Stuttgart/Bad Cannstatt: F. Fromman, 1965-1967.

Astarloa, Pablo Pedro, 1803. Apología de la lengua bascongada, ó ensayo crítico filosófico de su perfeccion y antigüedad sobre todas las que se conocen: en respuesta á los reparos propuestos en el Diccionario geográfico histórico de España, tomo ii, palabra Nabarra. Madril: G. Ortega. Berrargit. faksim. Bilbo: Amigos del Libro Vasco, 1983; Valentzia: Librerías "París-Valencia", 1993. , 1804. Reflexiones filosóficas en defensa de la Apología de la lengua vascongada, ó Respuesta á la censura crítica del cura de Montuenga. Madril: Cano. 
1883. Discursos filosóficos sobre la lengua primitiva ó Gramática y análisis razonada de la euskara ó bascuence. Bilbo: P. Velasco. Berrargit. faksim. Bilbo: Amigos del Libro Vasco, 1988.

Auroux, Sylvain (arg.), 1992. Histoire des idées linguistiques. Tome 2. Liège: Mardaga. \& Geneviève Clerico, 1992. "France". In Auroux, arg. 1992, 359-386.

Castaños, Florentino, 1978. Astarloa y la lengua vasca. (Temas Vizcaínos, 40). Bilbo: CAV.

Conde, José Antonio [“Cura de Montuenga"], 1804. Censura crítica de la pretendida excelencia y antigüedad del vascuence. Madril: Imprenta Real.

David, Madeleine V., 1992. "L'accès aux plus anciens textes: histoire du problème égyptien”. In Auroux, arg. 1992, 522-537.

Delattre, P[ierre]., 1949-56. Les établissements des jesuites en France despuis quatre siècles. Enghien: Institut Supérieur de Théologie.

Dominicy, Marc, 1992. "Le programme scientifique de la grammaire générale". In Auroux, arg. 1992, 424-441.

Donzé, Roland, 1967. La grammaire générale et raisonnée de Port-Royal. Contribution à l'histoire des idées grammaticales en France. Berna: A. Franke. Gazt. itz. Buenos Aires: Eudeba, 1973.

Droixhe, Daniel, 1978. La linguistique et l'appel de l'histoire (1600-1800). Genève: Droz.

Du Halde, Jean Baptiste (arg.), 1702-1776. Lettres édifiantes et curieuses écrites des missions étrangères par quelques missionaires de la Compagnie de Jésus. Paris.

Du Halde, Jean Baptiste, 1735. Description Géographique Historique, Chronologique, Politique Et Physique De L'Empire De La Chine Et De La Tartarie Chinoise Enrichie De Cartes générale Et Particulières du Thibet, \& de la Corée, \& ornée d'un grand nombre de Figures \& de Vignettes gravées en Taille-douce. Paris: P. G. Le Mercier.

Gárate, Justo, 1933. Guillermo de Humboldt. Estudio de sus trabajos sobre Vasconia. Bilbo: Junta de Cultura Vasca.

1933-34. "Correcciones y adiciones a la 1ª Sección del segundo volumen de la obra intitulada el Mithridates sobre la Lengua Cantábrica ó Vasca por Guillermo de Humboldt en Berlín año de 1817, en la Librería de Voss". RIEV 24.460-487; 25.87126. Ik. Humboldt 1817. 
1934. "Cinco cartas inéditas de Guillermo de Humboldt". RIEV 25.430-444, 622-639.

1936. La época de Pablo Astarloa y Juan Antonio Moguel. Bilbo: Junta de Cultura Vasca.

Gómez, Ricardo, 1999. "El verbo en movimiento: una teoría sobre el verbo vasco de comienzos del XIX”. In M. Fernández, F. García \& N. Vázquez, arg. Actas del I Congreso Internacional de la Sociedad Española de Historiografía Lingüística, 347360. Madril: Arco/Libros.

, 2001. "Artículo y "artículo" en la tradición gramatical vasca". In M.

Maquieira, $\mathrm{M}^{\mathrm{a}}$ D. Martínez \& M. Villayandre, arg. Actas del II Congreso Internacional de la Sociedad Española de Historiografía Lingüística, 465-478. Madril: Arco/Libros.

, 2002. “Astarloaren ekarpena euskal gramatikaren ikerketetan”. Euskera $47: 2.857-867$.

2004 (inprimategian). "Pablo Astarloa gaur egungo ikuspegitik". LARIZ. Durango eta Durangaldeko historia, arte eta kultura urtekaria 1.

\& Joseba A. Lakarra (arg.), 1992. Euskalaritzaren historiaz, I: XVI-XIX. mendeak. (ASJU-ren gehigarriak, 25). Donostia: Gipuzkoako Foru Aldundia/EHU.

Harbsmeier, Christoph, 1992. "La connaissance du chinois”. In Auroux, arg. 1992, 299312.

Harnois, Guy, 1929. Les théories du langage en France de 1600 à 1821. Paris: Les Belles Lettres.

Hervás, Lorenzo, 1784. Catalogo delle lingue conosciute e notizia della loro affinitá, e diversitá. (Idea dell'Universo, XVII). Cesena: G. Biasini. Berrargit. faksim. in Tovar 1987, 95 hh.

, 1785. Trattato dell'origine, formazione, mecanismo, ed armonia degl'idiomi. (Idea dell'Universo, XVIII). Cesena: G. Biasini.

1786. Arithmetica delle Nazioni, e divisione del tempo fra gli Orientali. (Idea dellÚniverso, XIX). Cesena: G. Biasini.

1787a. Vocabolario poliglotto, sopra più cl lingue. (Idea dell'Universo, XX).

Cesena: G. Biasini. Berrargit. faksim. in Breva Claramonte \& Sarmiento (arg.) 1991, 39-286.

1787b. Saggio pratico delle lingue, con prolegomeni e una raccolta di orazioni dominicali in più di trecento lingue e dialetti. (Idea dell'Universo, XXI). 
Cesena: G. Biasini. Berrargit. faksim. in Breva Claramonte \& Sarmiento (arg.) 1991, 287-541.

Humboldt, Wilhelm von, [1810-1815]. "Quellen u. Hülfsmittel zum Studium der Vaskischen Sprache". In Analyse der vaskischen Sprache, eskuizk. argitaragabea. Gazt. itz.: "Fuentes y medios auxiliares para el estudio de la lengua vasca". In Gárate $1933,135-152$.

1817. Berichtigungen und Zusätze zum ersten Abschmitte des zweiten Bandes des Mithridates über die Cantabrische oder Baskische Sprache. Berlin: Vossischen Buchhandlung. Gazt. itz. in Gárate 1933-34.

Hurch, Bernhard, Ricardo Gómez \& Ma Jose Kerejeta, 2002. “Zum Stellenwert Astarloas und des Plan de Lenguas". In B. Hurch, arg. Die baskischen Materialien aus dem Nachlaß Wilhelm von Humboldts. Astarloa, Fréret, Charpentier, Aizpitarte und anderes, 21-42. Paderborn: Schöningh.

Juliard, Pierre, 1970. Philosophies of Language in Eighteenth-Century France. The Hague/Paris: Mouton.

Kircher, Athanasius, 1667. China monumentis quà sacris quà profanis, nec non variis naturae et artis spectaculis aliarumque rerum memorabilium argumentis illustrata. apud J. Jansonium a Waesberge \& E. Weyerstraet, Amstelodami.

Koerner, E. F. Konrad \& R. E. Asher (arg.), 1995. Concise History of the Language Sciences: From the Summerians to the Cognitivists. Oxford/New York: Pergamon.

Kuehner, Paul, 1944. Theories on the Origin and Formation of Language in the Eighteenth Century in France. Philadelphia: University of Pennsylvania.

Laka, Itziar, 1989. “Astarloaren hizkuntzalaritzaz”. ASJU 23:1.75-86. Berrargit. in Gómez \& Lakarra, arg. 1992, 367-378.

Lakarra, Joseba A., 1997. "Hizkuntz eskuliburuen tradizioa Euskal Herrian: I. L'interprect ou Traduction du François, Espagnol \& Basque ( 1620)”. ASJU 31:1.166. 1999. “L'interprect ou Traduction du François, Espagnol \& Basque ( 1620): II: Elkarrizketak". ASJU 33:2.493-568.

Larramendi, Manuel, 1745. Diccionario trilingüe del castellano, bascuence, y latin. Donostia: B. Riesgo y Montero. Berrargit. faksim. Txertoa, Donostia, 1984.

Manterola, Gabirel, 1921. "Durango'ko "Euskal-Egunetan" Manterola'tar Gabirel yaupariak irakurritako itzaldia”. In Lenengo euskalegunetako itzaldiak, 55-75. Bilbo: Euskaltzaindia. 
Mitxelena, Koldo, 1988 [1960]. Historia de la literatura vasca. Bigarren argit. Donostia: Erein. , 1973. "Gillaume de Humboldt et la langue basque". Lingua e stile 8.107-125.

Berrargit. in Mitxelena 1985, 126-142; berrargit. in Gómez \& Lakarra, arg. 1992, 379-393. 1985. Lengua e historia. Madril: Paraninfo.

Morpurgo Davies, Anna, 1998. History of Linguistics. IV: Nineteenth-Century Linguistics. Londres/New York: Longman.

Rocher, Rosane, 1995. "Discovery of Sanskrit by Europeans". In Koerner \& Asher (arg.) 1995, 188-191.

Salmon, Paul B., 1995. "Origin of Language Debate in the Eighteenth Century”. In Koerner \& Asher, arg. 1995, 184-187.

Simone, Raffaele, 1998. "The Early Modern Period". In G. C. Lepschy, arg. History of Linguistics. III: Renaissance and Early Modern Linguistics, 149-236. Londres/New York: Longman.

Swiggers, Pierre, 1984. Les conceptions linguistiques des Encyclopédistes: Étude sur la constitution d'une théorie de la grammaire au siècle des lumières. Heidelberg: J. Groos.

Tourneur, Victor, 1905. Esquisse d'une histoire des études celtiques. Liège: Université de Liège.

Tovar, Antonio, 1980. Mitología e ideología sobre la lengua vasca. Madril: Alianza Editorial.

Urgell, Blanca, 1997. "Estudios en torno a la historia de la lexicografía vasca". ASJU 31:2. 643-685.

Uriarte, José Mª 2002. Pablo Pedro Astarloa (1752-1806). Biografia. Durango: Arte eta Historia Museoa.

Villabaso, Camilo, 1887. "Euskaros ilustres. Biografía de D. Pablo Pedro de Astarloa". Euskal-Erria 17.33-39, 65-71.

Voltoire, s.d. [ca.1620]. L'Interprect ou Traduction du françois espagnol \& basque. Lyon: A. Rouyer. Ik. Lakarra 1997 eta 1999.

Wheeler, Garon, 1995. "Port-Royal Tradition of General Grammar". In Koerner \& Asher, arg. 1995, 169-174. 